\title{
The Path of the Combination of Medical Care and Pension-From the Perspective of Transaction Cost Theory
}

\author{
Gui-Ping FENG a ${ }^{\mathrm{a},}$, Yu WANG ${ }^{\mathrm{b}}$ and Ting-Kai JIANG ${ }^{\mathrm{c}}$ \\ Dalian University of Technology, Dalian, Liaoning, China

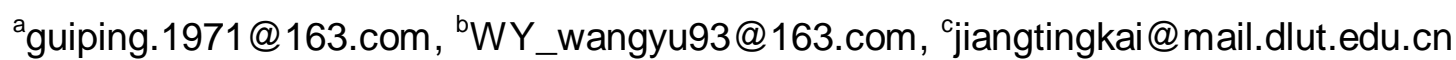 \\ ${ }^{*}$ Corresponding author
}

Keywords: Combination of medical care and pension, Transaction cost, Technologically separable interface.

\begin{abstract}
Based on transaction cost theory, this paper explains the logic of the combination of medical care and pension. The transaction costs which incurred in the transformation between medical care and pension for the elderly are firstly analyzed. Secondly, the medical-nursing combined mechanism of saving transaction costs, has been illustrated from the perspective of assets specificity, frequency, and uncertainty. Then comparing with the practice, this paper puts forward the path of the combination of medical care and pension from the aspects of environment, technology, and resource.
\end{abstract}

\section{Introduction}

As the trend of aging in China becomes more and more serious, a healthy elderly life has become an important topic of concern to the public. However, the state of general separation between medical care and pension has hindered the realization of healthy aging. As a response, a new pension mode of the combination of medical care and pension was being explored in the policies of State Council issues opinions on elderly care services (No.35[2013] of the State Council) and Notice of the General Office of the State Council on Forwarding the Guiding Opinions of the National Health and Family Planning Commission and Other Departments on Advancing the Combining of Medical and Health Services and Elderly Care Services (No.84[2015] of the General Office of the State Council) to promote the process of healthy pension.

However, for the definition of the combination of medical care and pension, there is still no consensus reached. In the early studies, most of the researches understood the combination of medical care and pension from the perspective of institution pension mode. They thought of it as an integration of nursing and medical institutions and its realization mainly through three modes: establishing medical institutions in nursing institutions, founding medical-nursing combined institutions in medical institutions, and establishing cooperation between nursing and medical institutions[1]. In the recent years, with the development of theory and practice, scholars' understanding of the combination of medical care and pension has been deepening and its connotation has been expanded to families and communities, no longer limited to the institutional level.

The combination of medical care and pension adapts to the requirements of healthy ageing, while in practice, the generally low integration of medical care and pension plays a limited role. A further study in the logic of medical-nursing combination and how it works can help us find which factors influence it works and put forward a targeted proposal. However, current studies, which mainly focus on its connotation, mode, what problems exist, and how to solve it, lack of a discussion on the logic of the combination of medical care and pension. In previous researches, scholars explained the combination of medical care and pension from the perspective of resources integration which mainly based on sociology and management. Zhang Xiaojie pointed out that the logic of the combination of medical care and pension is an ongoing process of mutual integration of medical and nursing services[2]. Wang Yufen stated that the nature of the combination of medical care and pension is a deep combination between medical care and pension at both resources and institutions level[3]. Yet these explanations are just an answer to the combination of medical care and pension at the phenomenon level, which is insufficient for elucidating its deep logic. 
On the basis of resources combination, this article try making a further analysis to elucidate the logic of the combination of medical care and pension from the perspective of economics with transaction cost theory, and exploring the path of it.

\section{Analysis of the Combination of Medical Care and Pension from the Perspective of Transaction Cost}

\section{How the Transaction Costs Occur and Their Origin between Medical Care and Pension}

Williamson thought that "a transaction occurs when a good or service is transferred across a technologically separable interface", when the interface is frictional, transaction costs occur and then the transfer can be hindered [4]. In this context, the shift between medical care and pension of providing for the aged can be seen as a transfer in a technologically separable interface. In consideration of the generally poor state of health of elderly, if the interface between medical care and pension is not well-working, a series of transaction costs can be caused with frequent transfers.

American scholar E.G. Furubotn and German researcher R. Rudolf pointed out that transaction costs can be classified into three types: market transaction costs, managerial transaction costs, and political transaction costs[5]. For the aged, in the transfer between medical care and pension services, the transaction costs refer to market transaction costs, mainly including three kinds. First of all, traffic costs. The aged often seek medical service and run between nursing and medical institutions, which causes traffic costs in the process of transaction. The next, time cost. When the aged get ill, especially sudden illness, they need to contact with medical institutions or go to hospital by themselves. In the process, they may delay treatment for many kinds of uncertainties, which reflects time cost of transaction. Lastly, lost labor incomes for time missed from work. When the sons or daughters take care of their parents during the illness, the costs incur, and this type of care often needs a long time.

\section{Why the Combination of Medical Care and Pension Can Save Transaction Cost}

The combination of medical care and pension integrates pension with medical care at both resources and institutions level, which satisfies the demands of elderly when they frequently transfer in the technologically separable interfaces between medical care and pension, saving unnecessary transaction costs in the process of transformation, and improving the economy and effectiveness of a healthy aged life. Williamson thought that assets specificity, uncertainty, and frequency are the principal dimensions for describing transactions[4]. In view of the reality of the combination of medical care and pension, the mechanism it can save transaction costs will be explained from the following three aspects in this paper.

Firstly, Assets Specificity. Williamson pointed out that assets specificity are usually distinguished into site specificity; physical asset specificity; human asset specificity and dedicated assets[4], which, in the medical-nursing combined mode, mainly refers to site specificity. And it is emphasized by Williamson that successive stages of production should be as close as possible to each other[4]. In the practice of the combination of medical care and pension, the integration between nursing and medical institutions is mainly by internal integration or cooperating between two closer institutions. Both way take advantage of the features of assets specificity, shortening the round distance of transactions between medical care and pension, and as a result saving the traffic costs when transactions recur.

Secondly, Frequency. It refers to the number of transaction over a period of time. "Recurrent transactions will support a highly specialized governance structure"[4]. In the medical-nursing separated mode, the elderly are more dependent on their children's care, particularly some with chronic diseases. While under the medical-nursing combined mode, there are special nursing staffs in the pension institutions, as well as the pension service center supplied by community, which can lower the reliance on children for the elderly who are recovering from illness or suffering from chronic diseases, reducing the frequency of child care, and thus cutting down the costs of children for loss of working time.

Thirdly, Uncertainty. It mainly includes the uncertainty of environment and behavior, the former varies according to the objective environment, while the latter is mainly caused by lacking of information, generally speaking, the transaction costs are positively correlated with the uncertainty[6]. In the medical-nursing separated mode, the elderly may delay treatment due to many kinds of environmental or 
human factors, causing time cost of the transaction. Yet the combination of medical care and pension can make a quick response to various emergencies so that the uncertainty of transaction and the resulting time cost can be cut down.

\section{The Path of the Combination of Medical Care and Pension from the Perspective of Transaction Cost}

Based on the above analysis, we can find that the saving of transaction costs is an important way for the combination of medical care and pension counting. However, in practice, a low level of the combination of medical care and pension generally existing restricts its effectiveness and value of saving transaction costs. Therefore, on the basis of transaction cost, this paper proposes the path of the combination of medical care and pension from the environment, technology and resource dimensions. As shown in Fig. 1, the study suggests to, for elderly reciprocating transactions, create an suitable environment by establishing a medical-nursing interaction alliance, and then give support from the technology and resource aspects.

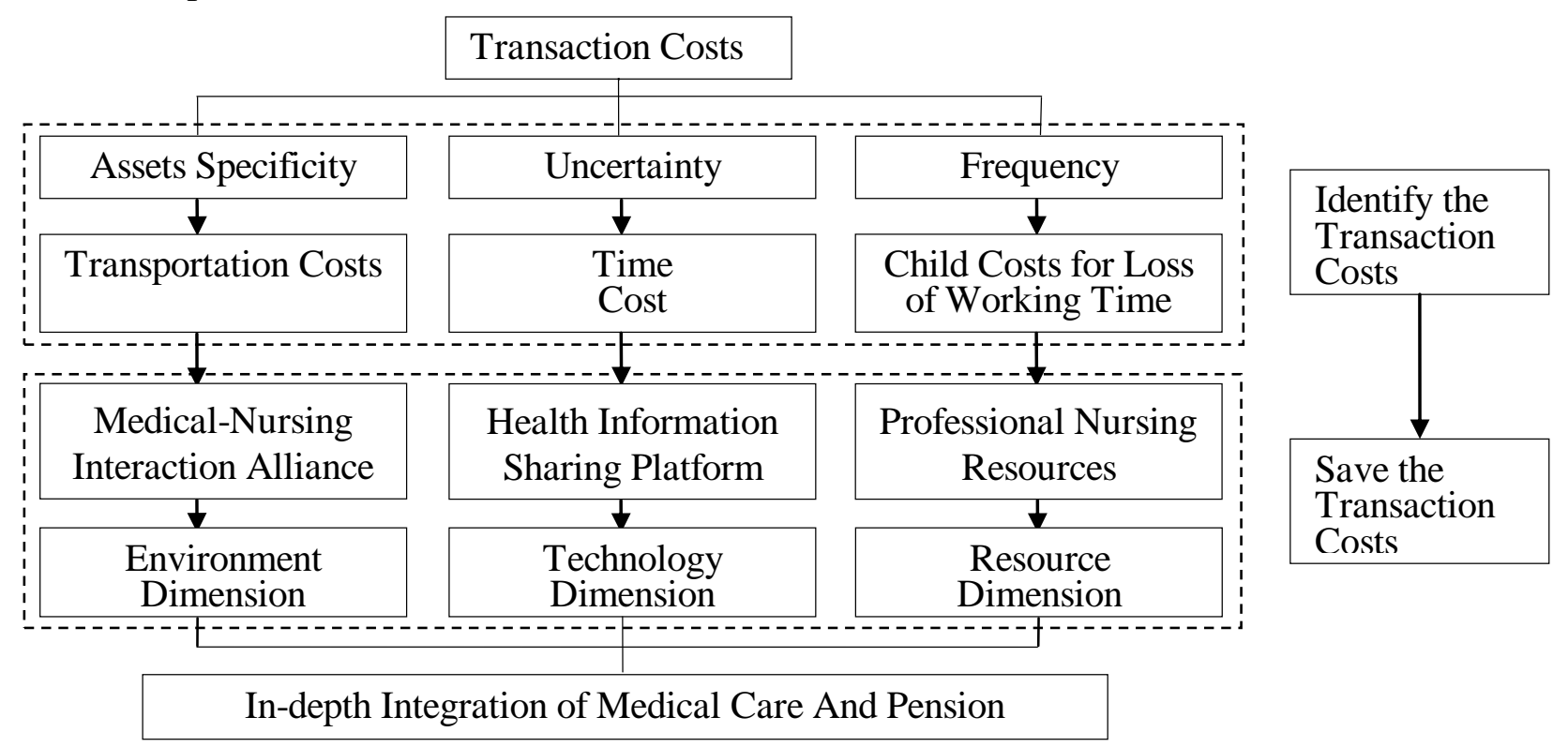

Fig. 1 The path of the combination of medical care and pension based on transaction cost

Firstly, A Regional Medical-nursing Interaction Alliance is Needed. The goal, of which, is to play a full supportive role of medical institutions at all levels. Then connecting the pension institutions, communities and families with them to maximize the advantage of adjacent location within the region, which can, in a degree, help and guide the elderly make use of the medical resources nearby, so as to reduce the transaction costs incurred by traffic. As far as the present development is concerned, there are three tasks need to be completed for establishing the alliance. In the first place, establish the regional medical association. The high-quality medical staffs should be encouraged to sink to primary healthcare institutions, as a result, the institutions' service capacity can be improved, which helps the medical demands of elderly be solved at the beginning of the medical service chain as far as possible; What's more, set up cooperation between communities or pension institutions and the medical association to provide a more stable medical condition for elderly, as well as more available medical service with door-to-door. In addition, promote the contracting and door-to-door service of family doctors to offer more convenient medical service for elderly at home.

Then, A Regional Health Information Sharing Platform Should be Established to Support a Smooth Two-way Referral Mechanism. With the platform, the elderly health information can be shared among communities, nursing homes and the medical association, which can lower the transaction uncertainty and transfer barriers caused by information asymmetry. Moreover, based on the information sharing platform, the elderly within the interaction alliance shall be allowed to access to the green channel 
for medical treatment so that they can receive therapy timely when facing sudden illness, thus to reduce the uncertainty brought by environment, and then, minimize time cost in the referral.

Finally, The Construction of Nursing Talents Needs to be Strengthened for Improving the Level of Elderly Basic Care. It is the general status that nursing talents is insufficient in China with small number and low quality. The care elderly can get is limited in pension institutions and can hardly obtain meticulous and considerate services, which is similarly to the pension service center of community because of the shortage of professional caregivers. Consequently, in the current situation, the dependency on children's care remained high for elderly of convalescent or with chronic diseases. Thus, the construction of nursing talents should be concerned to promote the combination of medical care and pension, which can satisfy the needs of elderly from resource dimension and reduce children's cost for loss of working time.

\section{Acknowledgement}

This research was financially supported by the National Social Science Foundation of China (16BGL147) - Research on the Mode and Path of Healthy Pension Based on Synergetic Development of Medical Care and Pension under the Background of "Internet Plus".

\section{References}

[1] Wen-Qian SUN, Xian-Cun DING, A Feasibility Study of the Combination of Medical Care and Pension in Public Hospitals: Based on Cases in Geriatric Department of Binhu Hospital in Hefei, J. Anhui Agric. Univ. (Soc Sci Ed). 22 (2013) 69-74.

[2] Xiao-Jie ZHANG, Study on Innovation of the Medical-nursing Combined Care Mode: Logic, Bottleneck and Policy Choices, Northwest population. 37 (2016) 105-111.

[3] Yu-Fen WANG, On Policies for the Combination of Nursing and Medical Care, China opening journal. 03 (2016) 75-80.

[4] O.E. Williamson, The Economic Institutions of Capitalism: Firms, Markets, Relational Contracting, first ed., China Social Sciences Publishing House, Beijing, 1999.

[5] E.G. Furubotn, R. Richter, Institutions and Economic Theory: The Contribution of the New Institutional Economics, translated by Jian-Qiang JIANG and Chang-Yuan LUO, first ed., Shanghai People's Publishing House, Shanghai, 2006.

[6] Cai-Xia SHANGGUAN, Shu-Yi FENG, Pei-Lu LV, Fu-Tian QU, Regional Differences of Rural Residential Land Replacement Modes and the Reasons in the Perspective of Transaction Cost Economics, China population, resources and environment. 24 (2014) 107-115. 